\title{
Molecular mechanisms of lead toxicity
}

\author{
MACIEJ SZYMAŃSKI \\ Laboratory of Bioinformatics, Institute of Molecular Biology and Biotechnology, Adam Mickiewicz University, Poznań, Poland \\ e-mail: mszyman@amu.edu.pl
}

\begin{abstract}
Lead is a ubiquitous xenobiotic metal and because of its widespread industrial use is one of the most serious environmental pollutants. Lead is highly toxic and exposure to even low doses can produce adverse effects on all living organisms. In humans, lead exposure can affect virtually all body systems, resulting in severe health problems. On a molecular level, lead can alter or interfere with the activity of proteins and nucleic acids, ultimately resulting in changes in cell metabolism and physiology leading to pathologic states. Lead can also affect the functions of macromolecules, directly or indirectly, by inducing oxidative stress, which is regarded as a primary factor in pathophysiology of lead exposure.
\end{abstract}

Key words: lead toxicity, heavy metal, oxidative stress, RNA damage, DNA damage, genomic instability

\section{Introduction}

Lead is the most abundant heavy metal present in the environment. Both metallic lead and its inorganic and organic salts have been known and widely used since ancient times. The Romans used lead and its alloys on a large industrial scale, utilizing it in the production of water pipes, tableware, and other objects of everyday use. In addition to industrial applications, various lead compounds were used as medicines for both external and internal use (Nriagu, 1992). Because of its sweet taste, lead acetate was also used as a sugar substitute. The sweet syrup commonly used in Ancient Rome to sweeten wine was obtained by boiling wine in lead pots. The use of the "sugar of lead" as a sweetener and possibly as an antibacterial agent in wine production continued until the $19^{\text {th }}$ century.

At the turn of the $20^{\text {th }}$ century, increasing amount of data indicated high toxicity of lead resulting in the prohibition of use of its compounds in medicinal applications, such as internal use drugs, and as food additives. In many countries, these findings also prompted legislative regulations aimed at limiting environmental lead exposure of the general population. In the past 40 years in the United States, the initial restrictions followed by a total bans on the use of lead and its compounds in household paints, plumbing, and as a gasoline additive, have resulted in over $90 \%$ reduction of the mean blood lead levels in children. Phasing out lead from automobile gasoline reduced atmospheric lead emission levels by 98\% when compared with the levels of the 1970s (Pirkle et al., 1994). Further reduction was achieved by limiting emission from metal ore processing and smelting plants. Despite these measures, lead still remains one of the most serious and health-threatening environmental pollutants. According to recent estimates, a significant fraction of U.S. children still have their blood lead levels higher than $5 \mu \mathrm{g} / \mathrm{dl}$, a value set by the Centers for Disease Control and Prevention as a reference value requiring medical intervention (Brink et al., 2013).

Given its widespread occurrence and persistence in the environment, lead is considered one of the most dangerous toxins. It poses serious health threats not only to individuals directly handling it, but also to general population, particularly in the environmentally degraded regions. In numerous studies, environmental and occupational lead exposure was linked to human diseases affecting cardiovascular, immune, renal, reproductive, skeletal, and nervous systems (Silveira et al., 2014; Zhang et al., 2012; Xie et al., 2013). The primary routes through which lead enters the human organism are respiratory and gastrointestinal systems. Over one-third of the absorbed lead enters the blood and is further dispersed into other tissues (Patrick, 2006). The blood lead levels are commonly used to assess the health risk. Lead concentrations of over $0.6 \mu \mathrm{M}$ are associated with health problems (Silbergeld, 2003), but they may be significantly 
higher (up to $10 \mu \mathrm{M}$ ) in the cases of occupational exposure (Hayes, 1997). Chronic exposure to lead correlates with certain forms of cancer, and the International Agency for Research on Cancer (IARC) included lead compounds in the list of probable carcinogens (GarcíaLestón et al., 2010).

The effects of lead exposure are more pronounced on the central nervous system, affecting its development and functioning. Lead is recognized as a neurotoxic agent affecting cognitive and behavioral functions. Prenatal and postnatal lead exposure constitutes a key factor in the development of brain (Cecil et al., 2008). There exists a high correlation between the lead blood levels in children and their cognitive abilities and social behavior. Even low level exposure to lead may result in significantly lower performance in the IQ tests (Jusko et al., 2008; Lanphear et al., 2005), antisocial behavior, and other symptoms of attention-deficit hyperactivity disorder (ADHD) (Froehlich et al., 2009).

\section{Molecular mechanisms of lead toxicity}

It is difficult to narrow down the causes of lead toxicity on a molecular level. Lead can affect proteins interfering with their enzymatic functions or the ability to bind other cellular components. Other mechanisms involve damage of nucleic acids and induction of oxidative stress. Lead exposure affects numerous cellular processes each of which may, to some extent, contribute to the clinical symptoms of lead poisoning (Fig. 1). The contribution of each mechanism may depend on the magnitude of exposure and/or cell type.

\section{Oxidative stress}

The major toxic effect of lead observed in animal and plant cells is the increase in the levels of reactive oxygen species (ROS). In aerobic organisms, the ROS are constantly generated in cells as by-products of many biochemical processes including respiration and natural anabolic and catabolic pathways. However, under normal conditions, the concentrations of various ROS are kept at safe levels by the activity of the antioxidant enzymes and synthesis of low molecular weight antioxidant compounds. The oxidative stress is a result of the imbalance between the production and scavenging of ROS. Essentially, such an imbalance can be brought about in two ways, either by increased ROS production or by an impaired ROS detoxification/scavenging system.
Overproduction of free radicals during oxidative stress causes damage to cellular structures, tissue damage, inflammatory response, and apoptosis. ROS can target proteins, nucleic acids, and lipids, leading to their modifications, damage, and inactivation (Djordjević, 2004). Increased production of free radicals can also have long-lasting effects and some of the chronic human diseases have been linked to oxidative stress (Bocci and Valacchi, 2013). In neural cells, increased production of ROS is regarded as one of the primary factors responsible for the development of neurodegenerative disorders such as Alzheimer's and Parkinson's (Breitenbach et al., 2013).

Lead not being a redox-active element cannot directly participate in the reactions leading to the formation of ROS; however, in erythrocytes a generation of ROS has been induced by its interaction with oxyhemoglobin (Ribarov and Bochev, 1982). However, the major contribution of lead to the onset and propagation of oxidative stress is by interfering with the enzymes and other cellular components of the defense system counteracting oxidative damage (Gurer and Ercal, 2000).

Glutathione (GSH), a tripeptide of glutamate, cysteine, and histidine, is one of the most important factors protecting cell components from ROS damage. Glutathione reduces disulfide bonds in proteins to cysteines using the sulfhydryl group of cysteine as a proton donor. In the process, GSH is converted to the oxidized form, glutathione disulfide (GSSH). Glutathione reductase (GR) reduces glutathione disulfide back to glutathione using NADPH as a proton donor (Franco et al., 2007). Glutathione oxidation is one of the elements of ROS detoxification and its decreased levels, accompanied by increased levels of GSSH, are frequently observed on exposure to lead (Aoyama and Nakaki, 2013; Kasperczyk et al., 2004, 2009, 2013). Lead has a twofold effect on the levels of glutathione. First, GSH was shown to form complexes with $\mathrm{Pb}^{2+}$ via the thiol groups of cysteine (Mah and Jalilehvand, 2012), and second, lead can inhibit the activity of glutathione reductase interfering with recycling of oxidized glutathione disulfide (Sandhir and Gill, 1995).

Although glutathione and its glutathione reductase seem to be the major targets of lead, other enzymes involved in ROS detoxification are also affected by lead exposure (Kasperczyk et al., 2012), thus contributing to the increased levels of free radicals in the cell. 


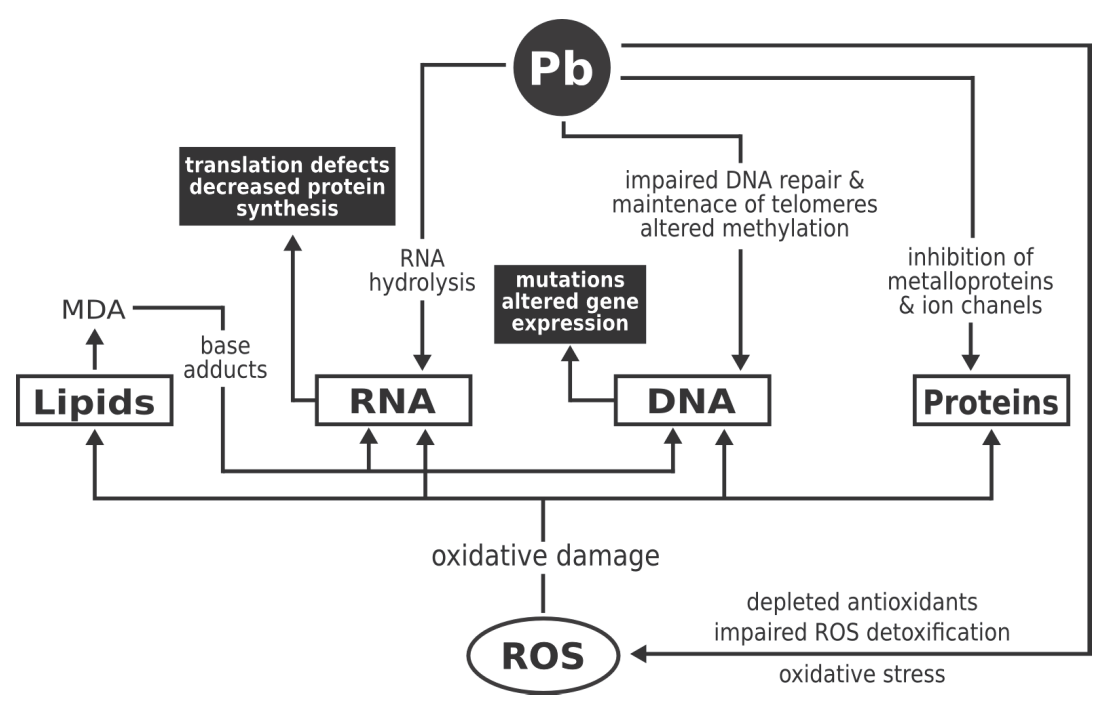

Fig. 1. Molecular targets of lead. Integrity and functions of biomolecules are affected by lead exposure directly or indirectly by promoting oxidative stress and increased levels of reactive oxygen species; see text for details

\section{Interactions with proteins}

Lead exposure was shown to affect many proteins, some of which play key roles in metabolic or regulatory pathways. Changes in the activity of enzymes or regulatory proteins can significantly contribute to its pathological state. It is assumed that $\mathrm{Pb}^{2+}$ can directly interfere with functions of proteins by binding thiol groups of cysteines or by ionic displacement, competing for binding with natural ligands of metal-dependent enzymes or ion transporters (Bridges and Zalups, 2005).

\section{$\delta$-aminolevulinic acid dehydratase}

One of the enzymes that is a common target of lead toxicity in animals and plants is $\delta$-aminolevulinic acid dehydratase (ALAD) also known as porphobilinogen synthase. ALAD catalyzes condensation of two molecules of $\delta$-aminolevulinic acid (ALA) to form the porphobilinogen, a precursor of heme, chlorophylls, cytochromes, and cobalamins. The ALAD activity depends on the binding of a divalent metal cation $\mathrm{Zn}^{2+}$ in animal, fungal, and bacterial ALADs and $\mathrm{Mg}^{2+}$ in plant enzymes (Senior et al., 1996). In mammals, ALAD is expressed in all cell types, with the highest expression levels found in liver and erythrocytes (Warren et al., 1998). Because of its sensitivity to lead, ALAD is commonly used as a biomarker of lead exposure, and studies on the effects of lead in occupationally exposed workers demonstrated that there is a strong negative correlation between the blood lead levels and ALAD activity (García-Lestón et al., 2012).
The results of several studies suggested that the susceptibility to toxic effects of lead could depend on the genetic factors involving ALAD. In human gene encoding ALAD, multiple single nucleotide polymorphisms (SNP) have been identified. One of these SNPs involving G-to-C transversion at position 177 within the coding region results in a lysine to asparagine substitution at position 59 of the protein sequence. The combinations of polypeptides encoded by the two alleles, ALAD1 (Lys) and ALAD2 (Asn), can produce three isoenzymes-ALAD1-1, ALAD1-2, and ALAD2-2-depending on the genotype. The isoenzymes can be distinguished based on the difference in the charge resulting from the substitution of positively charged lysine with neutral asparagine, and were proposed to have different sensitivity to inhibition by lead (Wetmur et al., 1991). The results of analyses of the correlation between blood lead levels and the frequencies of ALAD alleles are contradictory (Smith et al., 1995). In one study it was shown that ALAD2 allele correlates with higher blood lead concentrations, especially at high levels of exposure (Wetmur et al., 1991). On the other hand, a study on a group of occupationally exposed workers demonstrated that blood lead levels were higher in ALAD1 homozygotes than in heterozygotes (Yang et al., 2012).

The direct consequence of decreased enzymatic activity of ALAD is increase of the concentration of its substrate - the $\delta$-aminolevulinic acid ( $\delta$-ALA). An accumulation of $\delta$-ALA can induce production of ROS by eno- 
lization and auto-oxidation at physiological $\mathrm{pH}$, producing a superoxide anion (Bechara, 1996) or via coupled oxidation of oxyhemoglobin (Monteiro et al., 1986). The $\delta$-ALA accumulation can also affect the integrity of the DNA. 4,5-Dioxovaleric acid, the final product of $\delta$-ALA oxidation, was shown to be an alkylating factor capable of modifying guanines (DiMascio et al., 2000). Because its similarity with $\gamma$-aminobutyric acid (GABA), $\delta$-ALA can bind GABA receptors in the nervous system (Bellinger, 2011) and probably contribute to their oxidative damage (Adhikari et al., 2006) which could to some extent account for the neurotoxic effects of lead.

\section{Calcium-binding proteins}

Lead exposure was shown to affect the function of calmodulin $(\mathrm{CaM})$, a second messenger protein sensitive to fluctuations in the intracellular calcium levels. A unique feature of calmodulin is its ability to interact and regulate the activity of hundreds of proteins directly linked to changes in multiple cellular processes (Hoeflich and Ikura, 2002). Calmodulin is a highly conserved protein consisting of two globular domains, each containing two helix-loop-helix EF-hand motifs involved in binding $\mathrm{Ca}^{2+}$ ions (Hoeflich and Ikura, 2002). The binding or dissociation of calcium ions causes conformational changes altering calmodulin's affinity for the effector proteins (Park et al., 2008). Recent studies have demonstrated the fact that though lead shows higher affinity for both $\mathrm{N}$ - and $\mathrm{C}$-terminal domains of calmodulin than calcium ions, not all of the $\mathrm{Pb}^{2+}$ - and $\mathrm{Ca}^{2+}$-binding sites are the same. At low concentrations, $\mathrm{Pb}^{2+}$ binds the calcium-binding sites, which may result in the activation of calmodulin (Ouyang and Vogel, 1998). On the other hand, at higher concentrations of lead, $\mathrm{Pb}^{2+}$ displaces $\mathrm{Ca}^{2+}$ from two of its binding sites, but also binds with the linker region, altering its structure and preventing interactions with $\mathrm{CaM}$ target proteins (Kirberger et al., 2013). Thus, the impact of lead on calmodulin-dependent pathways may depend on the concentration of $\mathrm{Pb}^{2+}$. At low levels, lead may be responsible for hyperactivation, and at higher levels for inactivation.

Lead can also affect activities of other calcium-binding proteins. $\mathrm{Pb}^{2+}$ ions bind with a high-affinity calciumbinding site within osteocalcin, a protein involved in bone mineralization and resorption. In this case, the inhibitory effect of lead can interfere with bone mineral dynamics, which could explain the defects in the deve- lopment of the skeletal system in children exposed to lead (Dowd et al., 1994). Lead is also a strong inhibitor of the voltage-gated $\mathrm{Ca}^{2+}$ and $\mathrm{K}^{+}$channels (Atchinson, 2003) and an activator of calcium/phospholipid-dependent protein kinase $\mathrm{C}$, the proteins associated with many neuronal functions including learning and memory (Long et al., 1994).

\section{Zinc finger proteins}

Zinc finger motifs are protein domains involved in the sequence-specific recognition and thus binding of nucleic acids. The zinc finger fold is stabilized by one or two zinc ions coordinated by histidine and cysteine residues (Klug and Rhodes, 1987). Zinc finger proteins are essential components of gene regulatory networks and they participate in transcriptional activation of many essential genes involved in numerous processes (Klug, 1999; Laity et al., 2001). Because its affinity for thiol groups, $\mathrm{Pb}^{2+}$ can efficiently compete with $\mathrm{Zn}^{2+}$ for binding sites within cysteine-rich zinc fingers. The affinity of $\mathrm{Pb}^{2+}$ for zinc finger domains depends on the number of cysteines forming the metal-binding site. However, unlike zinc ions, $\mathrm{Pb}^{2+}$ are unable to stabilize the correct structure required for DNA binding (Payne et al., 1999). Substituting a native zinc ion with lead within the DNAbinding domain of a transcription factor can lead to a loss or alteration of its transcriptional activity.

The prototypic zinc finger protein is a transcription factor IIIA (TFIIIA) required for expression of $5 \mathrm{~S}$ ribosomal RNA containing nine Cys(2)His(2) zinc fingers involved in DNA and RNA binding. In vitro studies demonstrated that micromolar concentrations of lead inhibited binding of TFIIIA to the promoter region of 5S rRNA gene. The inability of lead to disrupt the TFIIIA-DNA complex after it has been formed suggests that it interfered with binding of zinc ions to zinc finger domain (Hanas et al., 1999).

Transcription factor $\mathrm{Sp} 1$ is involved in transcription of RNA polymerase II-dependent genes from promoters rich in GC elements. The DNA-binding domain of Sp1 consists of three zinc fingers binding the GC box (Li and Davie, 2010). Mapping of the transcription binding sites in human genome revealed that $\mathrm{Sp} 1$ can bind at least 12,000 sites (Cawley et al., 2004) associated with promoters of genes encoding proteins involved in a wide variety of processes including growth, apoptosis, angiogenesis, immune response, neural functions, and chro- 
matin remodeling (Tan and Khachigian, 2009). Many of the Sp1 target genes are important in the initiation and progression of cancerogenesis (Li and Davie, 2010). A study on DNA binding and transcriptional activity of Sp1 has revealed that lead affects the formation of DNASp1 complex in vitro (Zawia et al., 1998; Hanas et al., 1999). Moreover, lead exposure alters expression profiles of Sp1-dependent genes involved in the development of the rat nervous system both in cell cultures and in vivo (Zawia et al., 1998). Similar changes in gene expression profiles in the developing rat brain were also observed for another zinc finger protein-containing transcription factor, Egr-1 (Reddy and Zawia, 2000).

These findings, although limited to a subset of developmentally regulated genes, suggest that by interfering with the activity of transcription factors, lead may affect expression of other genes, contributing to the pathophysiology of lead toxicity.

\section{Effects of lead on DNA}

Apart from inducing oxidative stress and interfering with the function of proteins, lead has a genotoxic effect affecting the integrity of a genetic material. Lead and its compounds were recognized as mutagenic factors (Roy and Rossman, 1992). These observations were further confirmed by epidemiological studies showing a correlation between elevated blood lead levels and an increased mutation rate and DNA damage (García-Lestón et al., 2012). In addition to the direct and indirect damages, lead can affect the structure of chromatin by influencing DNA methylation.

\section{Oxidative damage}

The oxidative damage of DNA was for a long time recognized as a major threat for cells, due to its farreaching biological consequences like carcinogenesis and aging. ROS can target all components of the DNA, deoxyribose, nucleobases, and phosphodiester bonds, resulting in hydrolysis of the phosphate-sugar backbone or modification of bases (D'Errico et al., 2008). Mutations resulting from the mispairing of modified bases and breaks in the sugar-phosphate backbone can have a profound effect on the expression and functions of affected genes. By promoting an oxidative stress and an increase in ROS concentration, lead can indirectly affect oxidation of bases in genomic DNA.

The oxidation of deoxyribose at the $5^{\prime}$ carbon produces furfural that can react with the amino group of adenine to produce kinetin (N6-furfuryladenine) (Barciszewski et al., 1997). The presence of kinetin in the DNA as a secondary product of DNA oxidation is potentially mutagenic. During the synthesis of a complementary strand, although DNA polymerase correctly incorporates thymine at the position opposite of kinetin, replication errors may arise from nucleotide mis-incorporations occurring in a vicinity of the modified base (Wyszko et al., 2003).

Oxidation of the nucleobases in DNA can result in several products, including 8-oxo-guanine, 8-oxo-adenine, thymine glycol, and 5-hydroxyuracil (Marnett, 2000). Owing to easy detection and quantification methods, the most extensively studied oxidized base in DNA is 8-oxo$\mathrm{dG}$, and its levels are often used as a marker for DNA damage (Mangal et al., 2009). Oxidation is a result of the reaction of the ROS with the bases, but it has been suggested that lead is important catalyst in the oxidation of guanine (Banu et al., 2012). Most of the modifications of bases have a mutagenic potential. It has been shown that by the possibility of pairing with adenine, 8-oxo-dG can induce $\mathrm{G} \rightarrow \mathrm{T}$ and $\mathrm{A} \rightarrow \mathrm{C}$ transversions (Cheng et al., 1992; McCulloch et al., 2009). Studies on the effects of other oxidized DNA nucleobases have revealed that 8-oxo-adenine, thymine glycol, and 5-hydroxyuracil are also highly mutagenic (Wang et al., 1998).

Interestingly, studies on developmental lead exposure on rat brains have demonstrated that the 8-oxo-G levels in exposed animals were elevated during aging, even though lead was no longer present in the environment. This suggests that lead-induced disturbances during development can have long-term effects stimulating neurodegeneration in the aging animals (Bolin et al., 2006).

\section{Base adducts}

One of the major targets of oxygen radicals within the cell are polyunsaturated fatty acids in phospholipids. Apart from the influence on the integrity of cellular membranes, oxidation of lipids produces a range of highly reactive compounds, some of which can react with side chains of amino acids in proteins and bases in nucleic acids. They are reports that indicates peroxidation of lipids a major cause of endogenous DNA damage (Voulgaridou et al., 2011). One of the most abundant products of lipid peroxidation is malondialdehyde (MDA), which is frequently used as a marker of lead ex- 
posure. Under nonstress conditions, low levels of MDA, a by-product of prostaglandin biosynthesis pathway, are detectable in the cells. Increased levels of MDA, as well as other aldehydes produced by lipid oxidation, can contribute to DNA damage, and consequent mutations, by forming exocyclic adducts with bases (Marnett, 2002; Voulgaridou et al., 2011). The deoxyguanosine adduct of MDA ( $\mathrm{M}_{1} \mathrm{G}-\left[3-\left(2^{\prime}\right.\right.$-deoxy-beta-D-erythropentofuranosyl) -pyrimido[1,2-alpha]-purin-10(3H)-one]) is present in the DNA from healthy human tissues, healthy at levels of 1-4 $\times 10^{-8}$ nucleotides. $M_{1} G$ was shown to be mutagenic in prokaryotic and eukaryotic cells, introducing point and frameshift mutations (Marnett, 2002; Yau, 1979, Maddukuri et al., 2010). $M_{1} G$ increase was also shown to induce cell cycle arrest, increased expression of p53 and p21 proteins, and inhibition of kinase activities associated with cyclins E and B (Ji et al., 1998).

\section{Maintenance of the telomeres}

One of the early outcomes observed within a few hours of lead treatment of the cells is the formation of $\gamma \mathrm{H} 2 \mathrm{Ax}$ foci, which is associated with the double-stranded DNA breaks (Scully and Xie, 2013). It was proposed that the DNA damage inducing the formation of $\gamma \mathrm{H} 2 \mathrm{Ax}$ foci resulted from a direct interaction between $\mathrm{Pb}^{2+}$ and chromosomal DNA (Gastaldo et al., 2007). An analysis of the lead-induced $\gamma \mathrm{H} 2 \mathrm{Ax}$ foci revealed that they are primarily associated with the telomeric regions (Pottier et al., 2013), suggesting the presence of uncapped or shortened telomeres recognized by the protein complexes responsible for repairing DNA damage as doublestrand breaks. An increased telomere loss and doublet formation in lead-treated cells were observed due to the presence of dysfunctional telomeres, possibly resulting from defects in the replication of the lagging strand (Pottier et al., 2013). The observed telomere instability may be due to the stabilization of the G-quadruplexes by $\mathrm{Pb}^{2+}$ ions. G-quadruplex structures consisting of stacked G-tetrad planes connected by Hoogsteen hydrogen bonds were shown to have been associated with telomeres in a wide range of organisms including humans (Millevoi et al., 2012). The studies on thermal stability of G-quadruplexes demonstrated that $\mathrm{Pb}^{2+}$ ions contribute to the formation of more compact and significantly more stable structures than those depending on stabilization by monovalent sodium or potassium ions (Liu et al., 2011). Such an explanation is also consistent with observations that telomeres instability resulting from inhibition of telomerase activity can be caused by other factors stabilizing (Zahler et al., 1991; Burger et al., 2005; Huang et al., 2008). Owing to the high stability of G-quadruplexes, replication of the telomeres requires their enzymatic unwinding, and the mutations affecting these enzymes are often associated with telomere instability (Web et al., 2013). Replacement of $\mathrm{K}^{+}$or $\mathrm{Na}^{+}$ ions in the telomeric G-quadruplexes by lead might render them inaccessible to the unwinding helicases.

The correlation between lead exposure and deficiencies in the maintenance of telomeres is consistent with epidemiological studies. An analysis of the correlation between long-term occupational exposure to lead and the telomere length in peripheral white blood cells was carried out on a group of laborers employed at one of the battery manufacturing factories in China. The telomere shortening was shown to have been primarily associated with the blood lead levels and the duration of the exposure (Wu et al., 2012), indicating that a loss of telomere maintenance is one of the consequences of the chronic lead exposure. When compared with intrachromosomal regions, telomeric sequences show much higher susceptibility to damage by oxidative stress. Such instability of telomeres might also be due to lower effectiveness of DNA repair (Ayouaz et al., 2008; Kong et al., 2013).

\section{DNA repair}

The maintenance of the genome integrity being essential for the functioning and viability of the cells, there exist efficient mechanisms of DNA repair preventing propagation of damages introduced by mutagenic agents. In addition to its involvement in the processes leading to DNA damage, lead was also shown to affect the process of DNA repair.

In mammals, lead affects the DNA repair machinery by interfering with the activity of the apurinic/apyrimidinic endonuclease 1 (APE1/Ref-1) (McNeill et al., 2004). The inhibitory effect can be observed even at very low (below $1 \mu \mathrm{M}$ ) concentrations of metal ions, and in the genomic DNA of cultured Chinese hamster ovary cells, lead exposure results in an accumulation of apurinic/apyrimidinic sites (McNeill et al., 2007). APE1 is an ortholog of the bacterial Xth nuclease and is important in the DNA base excision repair (BER) at the abasic sites and single-stranded breaks produced as a result of 
oxidative stress and base modifications with alkylating agents (Mol et al., 2000a; Teebor et al., 2004). APE1 nicks the DNA upstream of the abasic sites in an $\mathrm{Mg}^{2+}$-dependent reaction. The resulting gap is subsequently filled in by the DNA polymerase. It has been suggested that the inhibition of nucleolytic activity of APE1 might be because of the binding of the $\mathrm{Pb}^{2+}$ ions with the two divalent cation-binding sites revealed in the crystal structure of the protein (Beernink et al., 2001). Subsequent studies using NMR demonstrated that the lead-dependent inhibition of the activity of APE1 involves direct interaction between $\mathrm{Pb}^{2+}$ and a conserved histidine responsible for the catalysis (Lowry et al., 2003).

In addition to the hydrolytic activity against apurinic/apyrimidinic sites, the APE1 was shown to possesses other nucleolytic activities of 3 DNA phosphodiesterase/phosphatase (Demple and Harrison, 1994), $3 \rightarrow 5$ DNA exonuclease, and RNase activity (Kim et al., 2014). Nucleolytic activities of APE-1 depend on the same catalytic center involving the conserved His309 residue responsible for $\mathrm{Pb}^{2+}$ binding (Mol et al., 2000b). Thus, under the conditions of lead overload, it is likely that all of these functions would be impaired.

The association between genotoxic effects of lead and the ability of cells to deal with DNA damages is also consistent with the observation that the extent of DNA damage does not depend exclusively on the lead levels. Differences in various indices of genotoxicity in leadexposed individuals were shown to correlate with polymorphisms in genes involved in DNA repair, including APE1, DNA ligase 4 (LIG4), X-ray repair cross-complementing protein 4 (XRCC4), and 8-oxoguanine glycosylase (OGG1) (García-Lestón et al., 2012).

\section{DNA methylation}

The gene expression depends to a great extent on the epigenetic modifications of the chromatin. One of the key epigenetic marks is methylation of cytosines producing 5-methylcytosine $(\mathrm{m} 5 \mathrm{C})$ in the DNA. DNA methylation is involved in the regulation of gene expression (Blattler and Farnham, 2013; Kulis et al., 2013), in the regulation of chromatin structure, and in genomic imprinting (Weaver and Bartolomei, 2014). Correct methylation patterns are vital for the development, establishment, and maintenance of cell identity (Koh and Rao, 2013). The changes in global methylation of the genomic DNA or altered methylation patterns on the levels of particular genes can contribute to the development of various pathologies, including cancer and neurological disorders (Brocato and Costa, 2014).

Exposure to lead as well as to other heavy metals was shown to have been associated with altered DNA methylation status (Jirtle and Skinner, 2007; Reichard et al., 2007; Sciandrello et al., 2004). It is predicted that the changes in DNA methylation may constitute a link between environmental exposure to lead (or other heavy metals) and some of the exposure-associated diseases. They could also account for the latency between lead exposure and the appearance of the syndromes of malignancies (Li et al., 2013). A direct link between lead exposure and the methylation status of DNA was shown in humans (Pilsner et al., 2009; Wright et al., 2010). An analysis of LINE-1 repetitive elements in the cultured cells and the occupationally exposed workers of the battery plant revealed that there is a significant inverse correlation between the lead exposure and the extent of DNA methylation ( $\mathrm{Li}$ et al. 2013). The altered DNA methylation was also proposed to account for a decreased activity of ALAD. An analysis of the methylation status of the ALAD gene revealed that occupational lead exposure correlates with increased methylation of the promoter-associated $\mathrm{CpG}$ islands, and consequently its reduced transcriptional activity (Li et al., 2011).

\section{Effects of lead on the functions of RNA}

The influence of lead exposure on the integrity of RNA molecules remains a largely unexplored territory. One of the reasons for this is the perception of the distinct roles played by the two types of nucleic acids in the cell. Being the repository of genetic information, DNA cannot be replaced, and its damages that can ultimately result in mutations endangering correct functioning or the viability of the cell must be promptly repaired. When compared with the consequences of DNA damage, the RNA damage does not seem to have such significant impact on the cellular functions. Damaged RNA can be replaced by correct transcripts, provided that the information contained in the DNA remains intact. On the other hand, unlike DNA, RNA molecules with some bases not involved in a secondary and tertiary structure formation and more readily accessible than paired bases within the DNA double helix may be more sensitive to damage by ROS produced during oxidative stress. A detailed analysis of nucleic acids isolated from cultured cell 
lines demonstrated that RNAs are in fact subject to oxidative damage to a much greater extent than DNA (Hoffer et al., 2005, 2006; Weimann et al., 2002). Although the oxidative RNA damage does not have any potentially lethal effect on the integrity of genetic information, it has been proposed that it may contribute to the pathophysiology of complex diseases including neurodegenerative disorders (Nunomura et al., 2012; Poulsen et al., 2012). Currently, there are no reports on the oxidative RNA damage in the context of lead exposure. However, given that the oxidative stress seems to be a major factor in lead toxicity, it is reasonable to believe that, just as DNA, RNA molecules are also targets of ROS-induced damage as is in the cases of other xenobiotic-inducing oxidative stress followed by RNA oxidation (Manini et al., 2009, 2010).

Similar to the case of oxidative damage of DNA, the major targets of RNA oxidation are the guanine-containing nucleotides. Since RNA polymerase can handle oxidized nucleoside triphosphates, it is possible that 8-oxo-G, as well as other oxidized bases, can be incorporated into RNA in the process of transcription. However, co-transcriptional incorporation cannot account for the amount of observed oxidized nucleotides in RNA. In the cell, there exist mechanisms for eliminating oxidized nucleoside di- and triphosphates by their enzymatic hydrolysis to monophosphates. Also, the incorporation of oxidized nucleotides into transcripts by RNA polymerase, when compared to their unoxidized counterparts, is much less efficient (Hayakawa et al., 1997; Nakabeppu et al., 1999, 2006; Taddei et al., 1997). The most obvious consequences of the presence of oxidized bases in RNA are deficiencies in the process of protein biosynthesis. Oxidized bases, having different base-pairing properties from those of their unmodified counterparts, may be a source of translational errors leading to the production of defective proteins or premature translation termination (Ishibashi et al., 2005; Tanaka et al., 2007).

Apart from the introduction of errors in proteins, mRNA oxidation may result in ribosome stalling or slowing down the translation and, ultimately, in a decreased expression of proteins, as evident from the increase in the amount of polyribosomes in the in vitro translation assays programmed with oxidized mRNA (Shan et al., 2007). A decreased efficiency of translation was also shown to be associated with the oxidation of nucleo- tides in the ribosomal RNA (Honda et al., 2005). Due to a slow turnover rate of rRNAs, such damage can have a long-lasting effect on cellular functions. Finally, there are data indicating that in extreme cases, RNA damage can lead to cell-cycle arrest and cell death in a p53-dependent or independent manner (Bellacosa and Moss, 2003). In addition to the indirect influence on the stability of RNA by promoting the production of ROS and oxidative damage, lead can also directly bind and hydrolyze RNA. Currently, the contribution of a specific targeting of RNA by lead ions to lead toxicity remains open.

An in vivo study aimed at determination of the impact of lead on the integrity of cellular mRNA in rabbit reticulocytes demonstrated that there was no difference in the amount of total RNA between the exposed and control animals. However, the RNA preparations from lead-treated cells were deficient in the in vitro translation assays and showed a significantly higher amount of free 5'-OH groups, suggesting RNA hydrolysis. Moreover, the ratio of polyribosomes to monoribosomes in the cells from animals exposed to lead was lower than in the unexposed controls. The in vitro experiments using globin mRNA treated with micromolar concentrations of $\mathrm{Pb}^{2+}$ suggested that the loss of translational activity of mRNA was due to RNA cleavage within the $5^{\prime}$-terminal region, although the detailed mechanism was not explored (Aethranis and Farkas, 1995). A specific leadinduced cleavage was also observed in 5S RNA, group I RNA intron, as well as ribosomal RNA (-[3-( 2 '-deoxybeta-D-erythropentofuranosyl)pyrimido[1,2-alpha]-purin10(3H)-one]; Winter et al., 1997). However, since the hydrolysis occurred at millimolar concentrations of $\mathrm{Pb}^{2+}$, it is unlikely that it could contribute to toxic effects of lead at physiological conditions. One of the first examples of RNA hydrolysis catalyzed by lead ions was the observation that $\mathrm{Pb}^{2+}$ promotes cleavage of the $\mathrm{D}$ loop of the yeast tRNA ${ }^{\text {Phe }}$ at a very low $\mathrm{Pb}^{2+}$ concentration (Werner et al., 1976; Brown et al., 1983). The reaction was also shown to occur in trans using different fragments of tRNA as catalysts and substrates (Deng and Termini, 1992). Based on these observations, the SELEX technique was used to isolate an RNA motif capable of selfcleavage in the presence of lead ions (Pan and Uhlenbeck, 1992a, 1992b). The lead-dependent ribozyme, or the leadzyme motif, is an asymmetric, purine-rich internal RNA loop closed by base-paired regions. The cleavage of cis- and trans-acting leadzyme is induced by 
micromolar concentrations of $\mathrm{Pb}^{2+}$ (Ohmichi et al., 1998; Pan et al., 1994). The formation of structures containing the leadzyme motif in cellular RNAs either in cis or in trans could result in a site-specific cleavage RNA at a sufficient concentration of $\mathrm{Pb}^{2+}$ ions. Such a possibility was demonstrated in tobacco plants infected with tobacco mosaic virus (TMV). The RNA oligonucleotide carrying a catalytic sequence of leadzyme and capable of forming a leadzyme motif with the target site within TMV RNA induced hydrolysis of the viral RNA and reduced its proliferation and propagation (Wyszko et al., 2006). Whether such a mechanism of lead-dependent specific RNA hydrolysis could contribute to lead toxicity in humans remains an open question.

\section{Acknowledgments}

This work was supported by grant N N301 254736 from the Polish Ministry of Science and Higher Education.

\section{References}

Adhikari A., Penatti C.A., Resende R.R., Ulrich H., Britto L.R., Bechara E.J. (2006) 5-Aminolevulinate and 4, 5-dioxovalerate ions decrease $G A B A(A)$ receptor density in neuronal cells, synaptosomes and rat brain. Brain Res. 1093: 95-104.

Aethranis C.A., Farkas W. (1995) Does the Pb(2+)-catalyzed depolymerization of RNA occur in vivo? Nucl. Acids Symp. Ser. 33: 109-114.

Aoyama K., Nakaki T. (2013) Impaired glutathione synthesis in neurodegeneration. Int. J. Mol. Sci. 14: 21021-21044.

Atchison W.D. (2003) Effects of toxic environmental contaminants on voltage-gated calcium channel function: from past to present. J. Bioenerg. Biomembr. 35: 507-532.

Ayouaz A., Raynaud C., Heride C., Revaud D., Sabatier L. (2008) Telomeres: hallmarks of radiosensitivity. Biochimie 90: 60-72.

Banu L., Blagojevic V., Bohme D.K. (2012) Lead(II)-catalyzed oxidation of guanine in solution studied with electrospray ionization mass spectrometry. J. Phys. Chem. B 116: 11791-11797.

Barciszewski J., Siboska G.E., Pedersen B.O., Clark B.F., Rattan S.I. (1997) A mechanism for the in vivo formation of N6-furfuryladenine, kinetin, as a secondary oxidative damage product of DNA. FEBS Lett. 414: 457-460.

Bechara E.J.H (1996) Oxidative stress in acute intermittent porphyria and lead poisoning may be triggered by 5-aminolevulinic acid. Brazilian J. Med. Biol. Res. 29: 841-851.

Beernink P.T., Segelke B.W., Hadi M.Z., Erzberger J.P., Wilson D.M. $3^{\text {rd }}$, Rupp B. (2001) Two divalent metal ions in the active site of a new crystal form of human apurinic/apyrimidinic endonuclease, Ape1: implications for the catalytic mechanism. J. Mol. Biol. 307: 1023-1034.
Bellacosa A., Moss E.G. (2003) RNA repair: damage control. Curr. Biol. 13: R482-484.

Bellinger D.C. (2011) The protean toxicities of lead: New chapters in a familiar story. Int. J. Environ. Res. Public Health 8: 2593-2628.

Blattler A., Farnham P.J. (2013) Cross-talk between site-specific transcription factors and DNA methylation states. J. Biol. Chem. 288: 34287-34294.

Bocci V., Valacchi G. (2013) Free radicals and antioxidants: how to reestablish redox homeostasis in chronic diseases? Curr. Med. Chem. 20: 3397-3415.

Bolin C.M., Basha R., Cox D., Zawia N.H., Maloney B., Lahiri D.K., Cardozo-Pelaez F. (2006) Exposure to lead and the developmental origin of oxidative DNA damage in the aging brain. FASEB J. 20: 788-790.

Breitenbach M., Ralser M., Perrone G.G., Iglseder B., Rinnerthaler M., Dawes I.W. (2013) Oxidative stress and neurodegeneration: the yeast model system. Front. Biosci. 18: 1174-1193.

Bridges C.C., Zalups R.K. (2005) Molecular and ionic mimicry and the transport of toxic metals. Toxicol. Appl. Pharmacol. 204: 274-308.

Brink L.L., Talbott E.O., Sharma R.K., Marsh G.M., Wu W.C., Rager J.R., Strosnider H.M. (2013) Do US ambient air lead levels have a significant impact on childhood blood lead levels: results of a national study. J. Environ. Public. Health 2013: 278042.

Brocato J., Costa M. (2014) Basic mechanics of DNA methylation and the unique landscape of the DNA methylome in metal-induced carcinogenesis. Crit. Rev. Toxicol. 43: 493-514.

Brown R.S., Hingerty B.E., Devan J.C., Klug A. (1983) Pb(II) -catalyzed cleavage of the sugar-phosphate backbone of yeast tRNA $A^{\text {Phe }}$ - implications for lead toxicity and self splicing $R N A$. Nature 303: 543-546.

Burger A.M., Dai F., Schultes C.M., Reszka A.P., Moore M.J., Double J.A., Neidle S. (2005) The G-quadruplex-interactive molecule BRACO-19 inhibits tumor growth, consistent with telomere targeting and interference with telomerase function. Cancer Res. 65: 1489-1496.

Cawley S., Bekiranov S., Ng H.H., Kapranov P., Sekinger E.A., Kampa D., Piccolboni A., Sementchenko A., Cheng J., Williams A.J. et al. (2004) Unbiased mapping of transcription factor binding sites along human chromosomes 21 and 22 points to widespread regulation of noncoding RNAs. Cell 116: 499-509.

Cecil K.M., Brubaker C.J., Adler C.M., Dietrich K.N., Altaye M., Egelhoff J.C., Wessel S., Elangovan I., Hornung R., Jarvis K. et al. (2008) Decreased brain volume in adults with childhood lead exposure. PLoS Med. 5: 0741-0749

Cheng K.C., Cahill D.S., Kasai H., Nishimura S., Loeb L.A. (1992) 8-Hydroxyguanine, an abundant form of oxidative $D N A$ damage, causes $G \rightarrow T$ and $A \rightarrow C$ substitutions. J. Biol. Chem. 267: 166-172.

D'Errico M., Parlanti E., Dogliotti E. (2008) Mechanism of oxidative DNA damage repair and relevance to human pathology. Mutat. Res. 659: 4-14. 
Demple B., Harrison L. (1994) Repair of oxidative damage to DNA: enzymology and biology. Annu. Rev. Biochem. 63: 915-948.

Deng H.Y., Termini J. (1992) Catalytic RNA reactions of yeast $t R N A^{\text {Phe }}$ fragments. Biochemistry 31: 10518-10528.

Di Mascio P, Teixeira PC, Onuki J, Medeiros MH, Dörnemann D, Douki T, Cadet J. (2000) DNA damage by 5-aminolevulinic and 4,5-dioxovaleric acids in the presence of ferritin. Arch. Biochem. Biophys. 373: 368-374.

Djordjević V.B. (2004) Free radicals in cell biology.Int. Rev. Cytol. 237: 57-89.

Dowd T.L., Rosen J.F., Gundberg C.M., Gupta R.K. (1994) The displacement of calcium from osteocalcin at submicromolar concentrations of free lead. Biochim. Biophys. Acta 1226: 131-137.

Franco R., Schoneveld O.J., Pappa A., Panayiotidis M.I. (2007) The central role of glutathione in the pathophysiology of human diseases. Arch. Physiol. Biochem. 113: 234-258.

Froehlich T.E., Lanphear B.P., Auinger P., Hornung R., Epstein J.N., Braun J., Kahn R.S. (2009) Association of tobacco and lead exposures with attention-deficit/hyperactivity disorder. Pediatrics 124: E1054-E1063.

Garcia-Leston J., Mendez J., Pasaro E., Laffon B. (2010) Genotoxic effects of lead: an updated review. Environ. Int. 36: 623-636.

García-Lestón J., Roma-Torres J., Vilares M., Pinto R., Prista J., Teixeira J.P., Mayan O., Conde J., Pingarilho M., Gaspar J.F., Pásaro E., Méndez J., Laffon B. (2012) Genotoxic effects of occupational exposure to lead and influence of polymorphisms in genes involved in lead toxicokinetics and in DNA repair. Environ Int 43: 29-36.

Gastaldo J., Viau M., Bencokova Z., Joubert A., Charvet A.M., Balosso J., Foray N. (2007) Lead contamination results in late and slowly repairable DNA double-strand breaks and impacts upon the ATM-dependent signaling pathways. Toxicol. Lett. 173: 201-214.

Gurer H., Ercal N. (2000) Can antioxidants be beneficial in the treatment of lead poisoning? Free. Radic. Biol. Med. 29: 927-945.

Hanas J.S., Rodgers J.S., Bantle J.A., Cheng Y.G. (1999) Lead inhibition of DNA-binding mechanism of Cys(2)His(2) zinc finger proteins. Mol. Pharmacol. 56: 982-988.

Hayakawa H., Hofer A., Thelander L., Kitajima S., Cai Y., Oshiro S., Yakushiji H., Nakabeppu Y., Kuwano M., Sekiguchi M. (1999) Metabolic fate of oxidized guanine ribonucleotides in mammalian cells. Biochemistry 38: 3610-3614.

Hayes R.B. (1997) The carcinogenicity of metals in humans. Cancer Causes Control 8: 371-385.

Hoeflich K.P., Ikura M. (2002) Calmodulin in action: Diversity in target recognition and activation mechanisms. Cell 108: 739-742.

Hofer T., Badouard C., Bajak E., Ravanat J.L., Mattsson A., Cotgreave I.A. (2005) Hydrogen peroxide causes greater oxidation in cellular RNA than in DNA. Biol. Chem. 386: 333-337.
Hofer T., Seo A.Y., Prudencio M., Leeuwenburgh C. (2006) $A$ method to determine RNA and DNA oxidation simultaneously by HPLC-ECD: greater RNA than DNA oxidation in rat liver after doxorubicin administration. Biol. Chem. 387: 103-111.

Honda K., Smith M.A., Zhu X., Baus D., Merrick W.C., Tartakoff A.M., Hattier T., Harris P.L., Siedlak S.L., Fujioka H. et al. (2005) Ribosomal RNA in Alzheimer disease is oxidized by bound redox-active iron. J. Biol. Chem. 280: 20978-20986.

Huang F.C., Chang C.C., Lou P.J., Kuo I.C., Chien C.W., Chen C.T., Shieh F.Y., Chang T.C., Lin J.J. (2008) G-quadruplex stabilizer 3, 6-bis(1-methyl-4-vinylpyridinium) carbazole diiodide induces accelerated senescence and inhibits tumorigenic properties in cancer cells. Mol. Cancer Res. 6: 955-964.

Ishibashi T., Hayakawa H., Ito R., Miyazawa M., Yamagata Y., Sekiguchi M. (2005) Mammalian enzymes for preventing transcriptional errors caused by oxidative damage. $\mathrm{Nu}-$ cleic Acids Res. 33: 3779-3784.

Ji C., Rouzer C.A., Marnett L.J., Pietenpol J.A. (1998) Induction of cell cycle arrest by the endogenous product of lipid peroxidation, malondialdehyde. Carcinogenesis 19: 1275-1283.

Jirtle R.L., Skinner M.K. (2007) Environmental epigenomics and disease susceptibility. Nat. Rev. Genet. 8: 253-262.

Jusko T.A., Henderson C.R., Lanphear B.P., Cory-Slechta D.A., Parsons P.J., Canfield R.L. (2008) Blood lead concentrations $<10 \mathrm{microg} / \mathrm{dl}$ and child intelligence at 6 years of age. Environ. Health Perspect. 116: 243-248.

Kasperczyk A., Machnik G., Dobrakowski M., Sypniewski D., Birkner E, Kasperczyk S. (2012) Gene expression and activity of antioxidant enzymes in the blood cells of workers who were occupationally exposed to lead. Toxicology 301: 79-84.

Kasperczyk S., Dobrakowski M., Kasperczyk A., Ostałowska A., Birkner E. (2013) The administration of $N$-acetylcysteine reduces oxidative stress and regulates glutathione metabolism in the blood cells of workers exposed to lead. Clin. Toxicol. 51: 480-486.

Kasperczyk S., Kasperczyk A., Ostalowska A., Dziwisz M., Birkner E. (2004) Activity of glutathione peroxidase, glutathione reductase, and lipid peroxidation in erythrocytes in workers exposed to lead. Biol. Trace Elem. Res. 102: 61-72.

Kasperczyk S., Kasperczyk J., Ostałowska A., Zalejska-Fiolka J., Wielkoszyński T., Swietochowska E., Birkner E. (2009) The role of the antioxidant enzymes in erythrocytes in the development of arterial hypertension among humans exposed to lead. Biol. Trace. Elem. Res. 130: 95-106.

Kim W.C., Ma C., Li W.M., Chohan M., Wilson D.M. 3rd, Lee C.H. (2014) Altered endoribonuclease activity of apurinic/apyrimidinic endonuclease 1 variants identified in the human population. PLoS One. 9: e90837.

Kirberger M., Wong H.C., Jiang J., Yang J.J. (2013) Metal toxicity and opportunistic binding of $\mathrm{Pb}(2+)$ in proteins. J. Inorg. Biochem. 125: 40-49 
Klug A. (1999) Zinc finger peptides for the regulation of gene expression. J. Mol. Biol. 293: 215-218.

Klug A., Rhodes D. (1987) Zinc fingers: a novel protein fold for nucleic acid recognition. Cold Spring Harb. Symp. Quant. Biol. 52: 473-482.

Koh K.P., Rao A. (2013) DNA methylation and methylcytosine oxidation in cell fate decisions. Curr. Opin. Cell. Biol. 25: 152-161.

Kong C.M., Lee X.W., Wang X. (2013) Telomere shortening in human diseases. FEBS J. 280: 3180-3193.

Kulis M., Queirós A.C., Beekman R., Martín-Subero J.I. (2013) Intragenic DNA methylation in transcriptional regulation, normal differentiation and cancer. Biochim. Biophys. Acta 1829: 1161-1174.

Laity J.H., Lee B.M., Wright P.E. (2001) Zinc finger proteins: new insights into structural and functional diversity. Curr. Opin. Struct. Biol. 11: 39-46.

Lanphear B.P., Hornung R., Khoury J., Yolton K., Baghurst P., Bellinger D.C., Canfield R.L., Dietrich K.N., Bornschein R., Green T. et al. (2005) Low-level environmental lead exposure and children's intellectual function: an international pooled analysis. Environ. Health Perspect. 113: 894-899.

Li C., Yang X., Xu M., Zhang J., Sun N. (2013) Epigenetic marker (LINE-1 promoter) methylation level was associated with occupational lead exposure. Clin Toxicol 51: 225229.

Li C., Xu M., Wang S., Yang X., Zhou S., Zhang J., Liu Q., Sun Y. (2011) Lead exposure suppressed ALAD transcription by increasing methylation level of the promoter $C p G$ islands. Toxicol. Lett. 203: 48-53.

Li L., Davie J.R. (2010) The role of Sp1 and Sp3 in normal and cancer cell biology. Ann. Anat. 192: 275-283.

Liu W., Fu Y., Zheng B., Cheng S., Li W., Lau T.C., Liang H. (2011) Kinetics and mechanism of conformational changes in a G-quadruplex of thrombin-binding aptamer induced by $P b^{2+}$. J. Phys. Chem. B 115: 13051-13056.

Long G.J., Rosen J.F., Schanne F.A. (1994) Lead activation of protein kinase $C$ from rat brain. Determination of free calcium, lead, and zinc by 19F NMR. J. Biol. Chem. 269: 834-837.

Lowry D.F., Hoyt D.W., Khazi F.A., Bagu J., Lindsey A.G., Wilson D.M. 3rd (2003) Investigation of the role of the histidine-aspartate pair in the human exonuclease III-like abasic endonuclease, Ape1. J. Mol. Biol. 329: 311-322.

Maddukuri L., Eoff R.L., Choi J.Y., Rizzo C.J., Guengerich F.P., Marnett L.J. (2010) In vitro bypass of the major malondialdehyde- and base propenal-derived DNA adduct by human Y-family DNA polymerases kappa, iota, and Rev1. Biochemistry 49: 8415-8424.

Mah V., Jalilehvand F. (2012) Lead(II) complex formation with glutathione. Inorg. Chem. 51: 6285-6298.

Mangal D., Vudathala D., Park J.H., Lee S.H., Penning T.M., Blair I.A. (2009) Analysis of 7,8-dihydro-8-oxo-2'-deoxyguanosine in cellular DNA during oxidative stress. Chem. Res. Toxicol. 22: 788-797.
Manini P., De Palma G., Andreoli R., Marczynski B., Hanova M., Mozzoni P., Naccarati A., Vodickova L., Hlavac P., Mutti A. et al. (2009) Biomarkers of nucleic acid oxidation, polymorphism in, and expression of, hOGG1 gene in styrene-exposed workers. Toxicol. Lett. 190: 41-47.

Manini P., De Palma G., Andreoli R., Mozzoni P., Poli D., Goldoni M., Petyx M., Apostoli P., Mutti A. (2010) Occupational exposure to low levels of benzene: biomarkers of exposure and nucleic acid oxidation and their modulation by polymorphic xenobiotic metabolizing enzymes. Toxicol. Lett. 193: 229-235.

Marnett L.J. (2000) Oxyradicals and DNA damage. Carcinogenesis 21: 361-370.

McCulloch S.D., Kokoska R.J., Garg P., Burgers P.M., Kunkel T.A. (2009) The efficiency and fidelity of 8-oxo-guanine bypass by DNA polymerases delta and eta. Nucl. Acids Res. 37: 2830-2840.

Marnett LJ (2002) Oxy radicals, lipid peroxidation and DNA damage. Toxicology 181-182: 219-222.

McNeill D.R., Narayana A., Wong H.K., Wilson D.M. 3rd (2004) Inhibition of Ape1 nuclease activity by lead, iron, and cadmium. Environ. Health Perspect. 112: 799-804.

McNeill D.R., Wong H.K., Narayana A., Wilson D.M. 3rd. (2007) Lead promotes abasic site accumulation and comutagenesis in mammalian cells by inhibiting the major abasic endonuclease Ape1. Mol. Carcinog. 46: 91-99.

Millevoi S., Moine H., Vagner S. (2012) G-quadruplexes in RNA biology. Wiley Interdiscip. Rev. RNA 3: 495-507.

Mol C.D., Hosfield D.J., Tainer J.A. (2000a) Abasic site recognition by two purinic/apyrimidinic endonuclease families in DNA base excision repair: the 3 ends justify the means. Mutat. Res. 460: 211-229.

Mol C.D., Izumi T., Mitra S., Tainer J.A. (2000b) DNA-bound structures and mutants reveal abasic DNA binding by APE1 and DNA repair coordination. Nature 403: 451-456.

Monteiro H.P., Abdalla D.S.P., Augusto O., Bechara E.J.H (1986) Generation of active oxygen species during coupled oxidation of oxyhemoglobin and $\delta$-aminolevulinic acid. Biochem. Biophys. Acta. 881: 100-106.

Nakabeppu Y., Kajitani K., Sakamoto K., Yamaguchi H., Tsuchimoto D. (2006) MTH1, an oxidized purine nucleoside triphosphatase, prevents the cytotoxicity and neurotoxicity of oxidized purine nucleotides. DNA Repair 5: 761-772.

Nakabeppu Y., Tsuchimoto D., Ichinoe A., Ohno M., Ide Y., Hirano S., Yoshimura D., Tominaga Y., Furuichi M., Sakumi K. (2011) Biological significance of the defense mechanisms against oxidative damage in nucleic acids caused by reactive oxygen species: from mitochondria to nuclei. Ann. N.Y. Acad. Sci. 1011: 101-111.

Nriagu J.O. (1992) Saturnine drugs and medicinal exposure to lead: a historical outline. In: Needleman HL (Ed.). Human lead exposure. CRC Press, Boca Raton, Florida, pp. 3-22.

Nunomura A., Moreira P.I., Castellani R.J., Lee H.G., Zhu X., Smith M.A., Perry G. (2012) Oxidative damage to RNA in aging and neurodegenerative disorders. Neurotox. Res. 22: $231-248$. 
Ohmichi T., Okumoto Y., Sugimoto N. (1998) Effect of substrate $R N A$ sequence on the cleavage reaction by a short ribozyme. Nucleic Acids Res. 26: 5655-5661.

Ouyang H., Vogel H.J. (1998) Metal ion binding to calmodulin: NMR and fluorescence studies. Biometals 11: 213-222.

Pan T., Dichtl B., Uhlenbeck O. (1994) Properties of an in vitro selected $\mathrm{Pb}^{2+}$ cleavage motif. Biochemistry 33: 9561-9565.

Pan T., Uhlenbeck O. (1992a) In vitro selection of RNAs that undergo autolytic cleavage with $\mathrm{Pb}^{2+}$. Biochemistry 31: 3887-3895.

Pan T., Uhlenbeck O. (1992b) A small metalloribozyme with a twostep mechanism. Nature 358: 560-563.

Park H.Y., Kim S.A., Korlach J., Rhoades E., Kwok L.W., Zipfel W.R., Waxham M.N., Webb W.W., Pollack L. (2008) Conformational changes of calmodulin upon $\mathrm{Ca} 2+$ binding studied with a microfluidic mixer. Proc. Natl. Acad. Sci. USA 105: 542-547.

Patrick L. (2006) Lead toxicity, a review of the literature. Part 1: Exposure, evaluation, and treatment. Altern. Med. Rev. 11: $2-22$.

Payne J.C., Horst M.A., Godwin H.A. (1999) Lead Fingers: $\mathrm{Pb}^{2+}$ Binding to Structural Zinc-Binding Domains Determined Directly. J. Am. Chem. Soc. 121: 6850-6855.

Pilsner J.R., Hu H., Ettinger A., Sánchez B.N., Wright R.O., Cantonwine D., Lazarus A., Lamadrid-Figueroa H., Mercado-García A., Téllez-Rojo M.M. et al. (2009) Influence of prenatal lead exposure on genomic methylation of cord blood DNA. Environ. Health Perspect. 117: 1466-1471.

Pirkle J.L., Brody D.J., Gunter E.W., Kramer R.A., Paschal D.C., Flegal K.M., Matte T.D. (1994) The decline in blood lead levels in the United States. The National Health and Nutrition Examination Surveys (NHANES). JAMA 272: 284-291.

Pottier G., Viau M., Ricoul M., Shim G., Bellamy M., Cuceu C., Hempel W.M., Sabatier L. (2013) Lead exposure induces telomere instability in human cells. PLoS One 8: e67501.

Poulsen H.E., Specht E., Broedbaek K., Henriksen T., Ellervik C., Mandrup-Poulsen T., Tonnesen M., Nielsen P.E., Andersen H.U., Weimann A. (2012) RNA modifications by oxidation: a novel disease mechanism? Free Radic. Biol. Med. 52: 1353-1361.

Reddy G.R., Zawia N.H. (2000) Lead exposure alters Egr-1 DNA-binding in the neonatal rat brain. Int. J. Dev. Neurosci. 18: 791-795.

Reichard J.F., Schnekenburger M., Puga A. (2007) Long term low-dose arsenic exposure induces loss of DNA methylation. Biochem. Biophys. Res. Commun. 352: 188-192.

Ribarov S.R., Bochev P.G. (1982) Lead-hemoglobin interaction as a possible source of reactive oxygen species A chemiluminescent study. Arch. Biochem. Biophys. 213: 288-292.

Roy N.K., Rossman T.G. (1992) Mutagenesis and comutagenesis by lead compounds. Mutat. Res. 298: 97-103.

Sandhir R., Gill K.D. (1995) Effect of lead on lipid peroxidation in liver of rats. Biol. Trace. Elem. Res. 48: 91-97.
Sciandrello G., Caradonna F., Mauro M., Barbata G. (2004) Arsenic-induced DNA hypomethylation affects chromosomal instability in mammalian cells. Carcinogenesis 25: 413-417.

Scully R., Xie A. (2013) Double strand break repair functions of histone H2AX. Mutat. Res. 750: 5-14.

Senior N.M., Brocklehurst K., Cooper J.B., Wood S.P., Erskine P., Shoolingin-Jordan P.M., Thomas P.G., Warren M.J. (1996) Comparative studies on the 5-aminolaevulinic acid dehydratases from Pisum sativum, Escherichia coli and Saccharomyces cerevisiae. Biochem. J. 320: 401-412.

Shan X., Chang Y., Lin C.L. (2007) Messenger RNA oxidation is an early event preceding cell death and causes reduced protein expression. FASEB J. 21: 2753-2764.

Silbergeld E.K. (2003) Facilitative mechanisms of lead as a carcinogen. Mutat. Res. 533: 121-133.

Silveira E.A., Siman F.D., de Oliveira Faria T., Vescovi M.V., Furieri L.B., Lizardo J.H., Stefanon I., Padilha A.S., Vassallo D.V. (2014) Low-dose chronic lead exposure increases systolic arterial pressure and vascular reactivity of rat aortas. Free Radic. Biol. Med. 67: 366-376.

Smith C.M., Wang X., Hu H., Kelsey K.T. (1995) A polymorphism in the $\delta$-aminolevulinic acid dehydratase gene may modify the pharmacokinetics and toxicity of lead. Environ. Health Perspect. 103: 248-253.

Taddei F., Hayakawa H., Bouton M., Cirinesi A., Matic I., Sekiguchi M., Radman M. (1997) Counteraction by MutT protein of transcriptional errors caused by oxidative damage. Science 278, 128-130.

Tan N.Y., Khachigian L.M. (2009) Sp1 phosphorylation and its regulation of gene transcription. Mol. Cell. Biol. 29: 2483-2488.

Tanaka M., Chock P.B., Stadtman E.R. (2007) Oxidized messenger RNA induces translation errors. Proc. Natl. Acad. Sci. U. S. A. 104: 66-71.

Teebor G.W., Marensein D.R., Wilson D.M. 3rd (2004) Human AP endonuclease (APE1) demonstrates endonucleolytic activity against AP sites in single-stranded DNA. DNA Repair 3: 527-533.

Voulgaridou G.P., Anestopoulos I., Franco R., Panayiotidis M.I., Pappa A. (2011) DNA damage induced by endogenous aldehydes: current state of knowledge. Mutat. Res. 711: 13-27.

Wang D., Kreutzer D.A., Essigmann J.M. (1998) Mutagenicity and repair of oxidative DNA damage: insights from studies using defined lesions. Mutat. Res. Fundam. Mol. Mech. Mutagen. 400: 99-115.

Warren M.J., Cooper J.B., Wood S.P., Shoolingin-Jordan P.M., (1998) Lead poisoning, haem synthesis and 5-aminolaevulinic acid dehydratase. Trends Biochem. Sci. 23: 217-221.

Weaver J.R., Bartolomei M.S. (2014) Chromatin regulators of genomic imprinting. Biochim. Biophys. Acta 1839: 169177

Webb C.J., Wu Y., Zakian V.A. (2013) DNA repair at telomeres: keeping the ends intact. Cold Spring Harb. Perspect. Biol. 5: a012666. 
Weimann A., Belling D., Poulsen H.E. (2002) Quantification of 8-oxo-guanine and guanine as the nucleobase, nucleoside and deoxynucleoside forms in human urine by highperformance liquid chromatography-electrospray tandem mass spectrometry. Nucleic Acids Res. 30: e7.

Werner C., Krebs B., Keith G., Dirheimer G. (1976) Specific cleavages of pure tRNAs by plumbous ions. Biochim. Biophys. Acta 432: 161-175.

Wetmur J.G., Kaya A.H., Plewinska M., Desnick R.J. (1991) Molecular characterization of the human delta-aminolevulinate dehydratase 2 (ALAD2) allele: implications for molecular screening of individuals for genetic susceptibility to lead poisoning. Am. J. Hum. Genet. 49: 757-763.

Winter D., Polacek N., Halama I., Streicher B., Barta A. (1997) Lead-catalysed specific cleavage of ribosomal RNAs. Nucleic Acids Res. 25: 1817-1824.

Wright R.O., Schwartz J., Wright R.J., Bollati V., Tarantini L., Park S.K., Hu H., Sparrow D., Vokonas P., Baccarelli A. (2010) Biomarkers of Lead Exposure and DNA Methylation within Retrotransposons. Environ. Health Perspect. 118: 790-795.

Wu Y., Liu Y., Ni N., Bao B., Zhang C., Lu L. (2012) High lead exposure is associated with telomere length shortening in Chinese battery manufacturing plant workers. Occup. Environ. Med. 69: 557-563.

Wyszko E., Barciszewska M.Z., Markiewicz M., Szymański M., Markiewicz W.T., Clark B.F., Barciszewski J. (2003) "Action-at-a distance" of a new DNA oxidative damage pro- duct 6-furfuryl-adenine (kinetin) on template properties of modified DNA. Biochim. Biophys. Acta 1625: 239-245.

Wyszko E., Nowak M., Pospieszny H., Szymanski M., Pas J., Barciszewska M.Z., Barciszewski J. (2006) Leadzyme formed in vivo interferes with tobacco mosaic virus infection in Nicotiana tabacum. FEBS J. 273: 5022-5031.

Xie X., Ding G., Cui C., Chen L., Gao Y., Zhou Y., Shi R., Tian Y. (2013) The effects of low-level prenatal lead exposure on birth outcomes. Environ Pollut 175: 30-34.

Yang Y., Wu J., Sun P. (2012) Effects of delta-aminolevulinic acid dehydratase polymorphisms on susceptibility to lead in Han subjects from southwestern. China. Int. J. Environ. Res. Public. Health. 9: 2326-2338.

Yau T.M. (1979) Mutagenicity and cytotoxicity of malondialdehyde in mammalian cells. Mech. Aging Dev. 11: 137-144.

Zahler A.M., Williamson J.R., Cech T.R., Prescott D.M. (1991) Inhibition of telomerase by G-quartet DNA structures. Nature 350: 718-720.

Zawia N.H., Sharan R., Brydie M., Oyama T., Crumpton T. (1998) Sp1 as a target site for metal-induced perturbations of transcriptional regulation of developmental brain gene expression. Brain Res. Dev. Brain Res. 107: 291298.

Zhang A., Hu H., Sánchez B.N., Ettinger A.S., Park S.K., Cantonwine D., Schnaas L., Wright R.O., Lamadrid-Figueroa H., Tellez-Rojo M.M. (2012) Association between prenatal lead exposure and blood pressure in children. Environ. Health Perspect. 120: 445-450. 